\title{
Immediate bronchodilator response in FEV1 as a diagnostic criterion for adult asthma
}

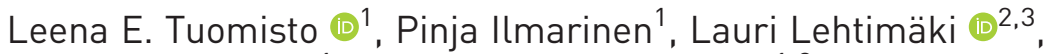 \\ Minna Tommola $\mathbb{\circledR}^{1}$ and Hannu Kankaanranta ${ }^{1,2}$ \\ Affiliations: \\ ${ }^{1}$ Dept of Respiratory Medicine, Seinäjoki Central Hospital, Seinäjoki, Finland. \\ ${ }^{2}$ Faculty of Medicine and Life Sciences, University of Tampere, Tampere, Finland. \\ ${ }^{3}$ Allergy Centre, Tampere University Hospital, Tampere, Finland. \\ Correspondence: \\ Leena E. Tuomisto, Dept of Respiratory Medicine, Seinäjoki Central Hospital, FIN-60220 Seinäjoki, Finland. \\ E-mail: leena.tuomistodepshp.fi
}

@ERSpublications

Not enough data exist to differentiate adult asthma patients from healthy subjects by $\triangle F E V 1 B D R$ http://ow.ly/hV0J30mIVkL

Cite this article as: Tuomisto LE, Ilmarinen $\mathrm{P}$, Lehtimäki L, et al. Immediate bronchodilator response in FEV1 as a diagnostic criterion for adult asthma. Eur Respir J 2019; 53: 1800904 [https://doi.org/10.1183/ 13993003.00904-2018].

ABSTRACT Asthma is characterised by variable and reversible expiratory airflow limitations. Thus, it is logical to use the change in forced expiratory volume in $1 \mathrm{~s}(\mathrm{FEV} 1)$ in response to a bronchodilator $\left(\triangle \mathrm{FEV}_{1} \mathrm{BDR}\right)$ as a diagnostic tool; increases of $\geqslant 12 \%$ and $\geqslant 200 \mathrm{~mL}$ from the baseline FEV 1 are commonly used values. We aimed to evaluate the historical development of diagnostic cut-off levels for the $\triangle$ FEV1BDR for adults and the evidence behind these recommendations.

We searched for studies from the reference lists of all the main statements, reports and guidelines concerning the interpretation of spirometry and diagnostics for asthma and conducted a literature search.

A limited amount of evidence regarding the $\triangle \mathrm{FEV} 1 \mathrm{BDR}$ in healthy populations was found, and even fewer patient studies were found. In healthy persons, the upper 95th percentile for the absolute $\triangle \mathrm{FEV} 1 \mathrm{BDR}$ ranges between $240 \mathrm{~mL}$ and $320 \mathrm{~mL}$, the relative $\triangle \mathrm{FEV}_{1} \mathrm{BDR}$ calculated from the initial FEV1 ranges from $5.9 \%$ to $13.3 \%$ and the $\triangle \mathrm{FEV}_{1 B D R}$ calculated from the predicted FEV1 ranges from $8.7 \%$ to $11.6 \%$. However, the absolute and percentage $\triangle \mathrm{FEV} 1 \mathrm{BDR}$ values calculated from the initial $\mathrm{FEV}_{1}$ are dependent on age, sex, height and the degree of airway obstruction. Thus, the use of the $\triangle \mathrm{FEV} 1 \mathrm{BDR}$ calculated from the predicted FEV1 might be more appropriate.

Not enough data exist to assess the sensitivity of any of the cut-off levels for the $\triangle \mathrm{FEV} 1 \mathrm{BDR}$ to differentiate asthma patients from healthy subjects. Further studies in newly diagnosed asthma patients are needed. 


\section{Introduction}

Obstructive lung diseases are defined as conditions in which airflow in the airways is decreased. Airflow obstruction can be fixed, as in chronic obstructive pulmonary disease (COPD), or variable, as in asthma. The diagnosis of asthma has generally been based on a long-term history of typical symptoms. In addition, objective lung function measurements have been recommended [1,2]. Significant reversibility of airway obstruction after inhalation of bronchodilator medication has been the main objective hallmark of asthma for decades [3-6]. The Global Initiative for Asthma (GINA) report prefers spirometry with a reversibility test as the first test if the patient's history or examination is suggestive of asthma [6].

An increase in forced expiratory volume in $1 \mathrm{~s}$ (FEV1) after inhalation of 200-400 $\mu \mathrm{g}$ of salbutamol or the equivalent $(\triangle \mathrm{FEV} 1 \mathrm{BDR})$ is considered significant if it is $\geqslant 12 \%$ and $\geqslant 200 \mathrm{~mL}$ when compared with the initial FEV1 [3, 5]. Hopp and PASHA [7] reviewed the paediatric literature regarding normal and abnormal improvements in FEV1 after administration of a bronchodilator. They found only a limited number of studies; the majority of them supported that a 9-10\% improvement in FEV1 could be clinically relevant. In contrast to previous assumptions that asthma is a disease that begins during childhood, recent studies have shown that most new asthma patients are diagnosed as adults $[8,9]$. Adult-onset asthma is less often atopic, and the role of disease-modifying factors, such as obesity, smoking, environmental exposures and comorbidities, is substantial [10-12].

Much of our knowledge on the nature and management of asthma is based on studies using a significant $\triangle \mathrm{FEV} 1 \mathrm{BDR}$ as a diagnostic criterion for diagnosing patients with asthma. The evidence behind the use of a bronchodilator response (BDR) to diagnose asthma in adults has not been reviewed. Differential diagnostics between asthma and COPD (or asthma-COPD overlap) and the choice of appropriate reference values and how they are used (e.g. \% predicted versus lower limit of normal) are not covered by this review. We evaluated the evidence behind the quantifiable improvement in FEV1 after administration of short-acting bronchodilator as a significant change or as a diagnostic method in adult asthma.

\section{Methods \\ Theoretical considerations for the use of the $\triangle F E V 1 B D R$ as a diagnostic tool in asthma}

Asthma is defined as "a heterogeneous disease, usually characterised by chronic airway inflammation. It is defined by the history of respiratory symptoms such as wheeze, shortness of breath, chest tightness and cough that vary over time and in intensity, together with variable expiratory airflow limitation" [6]. Thus, it is logical to use the $\triangle \mathrm{FEV} 1 \mathrm{BDR}$ as a diagnostic tool. However, to determine the appropriate cut-off points, their specificity and sensitivity, and the clinical value of a BDR to diagnose asthma, we consider that data regarding the following facts are necessary. 1) Values of $\Delta \mathrm{FEV} 1 \mathrm{BDR}>95$ th percentile in the healthy population are often considered abnormal. However, it is important to notice that this cut-off only separates "healthy" from "abnormal", i.e. it does not state that those with abnormal values have the specific disease of asthma rather than any other disease; 2) to obtain the sensitivity of the cut-off values for asthma diagnostics and to evaluate the overlap between healthy individuals and patients with asthma, the $\triangle \mathrm{FEV} 1 \mathrm{BDR}$ should be studied in therapy-naïve patients with asthma diagnosed by the gold standard method. As there is no gold standard method to diagnose asthma, we considered a combination of history and symptoms, other lung function measurements and evaluation by an asthma specialist as the appropriate standard; 3) in adults, other significant lung diseases (e.g. COPD, bronchiectasis and fibrosis) may cause obstruction and/or reduction in volume or flow parameters. To obtain the specificity of the cut-off values for asthma, the $\triangle \mathrm{FEV} 1 \mathrm{BDR}$ in other therapy-naïve relevant patient groups (as diagnosed by the gold standards specific to those diseases) should be studied. This allows evaluation of the specificity of a certain $\triangle \mathrm{FEV} 1 \mathrm{BDR}$ for diagnosing asthma.

To determine how well the $\triangle \mathrm{FEV} 1 \mathrm{BDR}$ has been characterised as a diagnostic tool for asthma, we searched the reference lists of all the main statements, reports and guidelines on the interpretation of spirometry and management of asthma. Most of them were published by the American Thoracic Society, European Respiratory Society, British Thoracic Society, National Heart, Lung, and Blood Institute and GINA (supplementary table S1). We conducted a literature search in PubMed (keywords: asthma, bronchodilator response, $\mathrm{FEV} 1)$. A common recommendation when assessing the $\triangle \mathrm{FEV} 1 \mathrm{BDR}$ is to perform spirometry before and after inhaled administration of $200-400 \mu \mathrm{g}$ of salbutamol or the equivalent $[5,6]$. Thus, we concentrated on the evidence obtained by measuring responses to a short-acting $\beta_{2}$-agonist. However, when appropriate, spontaneous variability or placebo responses may be mentioned. There is no consensus on the most reliable way to calculate and express the $\triangle \mathrm{FEV} 1 \mathrm{BDR}$. The three most commonly used methods are 1) absolute volume change ( $\mathrm{mL}$ or $\mathrm{L})$; 2) $\Delta \mathrm{FEV}_{1} \%$ of the initial $\mathrm{FEV}_{1}$; and 3$) \Delta \mathrm{FEV}_{1} \%$ of the predicted FEV1, all after bronchodilator administration (table 1). Other ways to measure the $\triangle$ FEV1BDR exist $[19,20]$, but as they are rarely used, they are not discussed in this review. 
TABLE 1 Three most common methods to calculate the immediate forced expiratory volume in $1 \mathrm{~s}$ (FEV 1 ) in response to a bronchodilator discussed in the recommendations, reports and guidelines for asthma and spirometry measurements

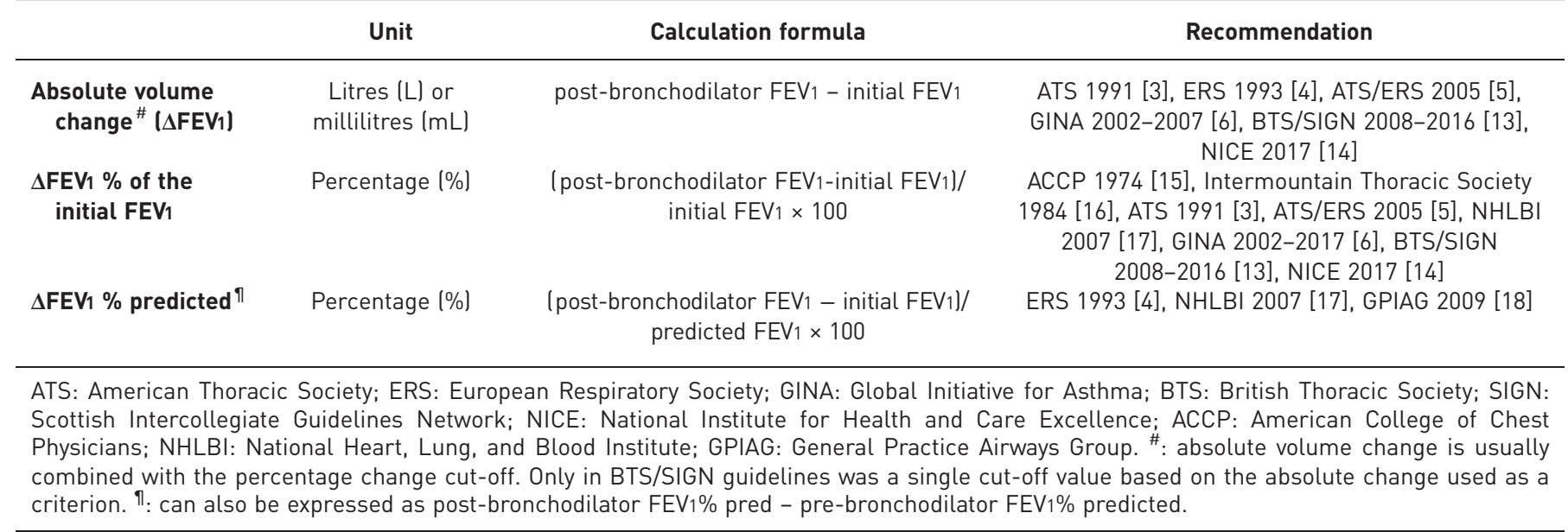

\section{Results}

Description of the BDR and historically suggested cut-off values

The historical development of the description and cut-off values for the immediate FEV1BDR in the recommendations, reports and guidelines on adult asthma or spirometry measurement are presented and briefly discussed in the supplementary material (table S1).

\section{Determination of the upper normal limit of the $\triangle F E V 1 B D R$ in healthy adults}

The main population-based studies on the $\triangle$ FEV1BDR are presented in supplementary table S2.

In larger (>200 persons) population-based samples of healthy subjects, the upper 95th percentiles of the absolute $\triangle \mathrm{FEV} 1 \mathrm{BDR}$ range between $240 \mathrm{~mL}$ and $320 \mathrm{~mL}$; the $\triangle \mathrm{FEV} 1 \%$ of the initial $\mathrm{FEV} 1$ range between $5.9 \%$ and $13.3 \%$; and the $\triangle \mathrm{FEV}_{1} \%$ of the predicted $\mathrm{FEV}_{1}$ range between $8.7 \%$ and $11.6 \%$ (table $\mathrm{S} 2$ ). However, the obtained absolute and $\triangle \mathrm{FEV} 1 \%$ of the initial FEV1 were dependent on sex, age, height and initial values, phenomena that were less significant with the $\triangle \mathrm{FEV}_{1} \%$ of the predicted FEV1 [22-25].

\section{Studies on the short-term variability in FEV1}

Patients with asthma have been proposed to have greater variability in FEV1 and less variability in the forced vital capacity (FVC) response to a bronchodilator than those with asthma-COPD overlap or COPD [24].

If the $\triangle \mathrm{FEV} 1 \mathrm{BDR}$ is considered a diagnostic marker, the response should be larger than natural short-term (e.g. $20 \mathrm{~min}$ ) variability in the FEV1 between two measurements or the response of FEV1 to a placebo inhaler. In a study group of patients with heterogeneous airway obstructions $(n=40)$ who were referred for pulmonary function evaluation, the FEV1 response was first measured compared to a placebo and then to an active bronchodilator [26]. Following placebo inhalation, the upper 95\% confidence limit of the absolute $\triangle \mathrm{FEV} 1 \mathrm{BDR}$ was $178 \mathrm{~mL}$ and the $\triangle \mathrm{FEV}_{1} \%$ of the initial $\mathrm{FEV}_{1}$ was $12.3 \%$. After that, a larger group of similar patients $(n=40+32)$ received a bronchodilator. Among this latter group of patients who received an active bronchodilator, $42 \%$ and $39 \%$ of the subjects reached the upper 95 th percentile limits of placebo-induced $\Delta \mathrm{FEV}_{1} \%$ of the initial $\mathrm{FEV}_{1}$ and absolute $\Delta \mathrm{FEV}_{1}$, respectively [26]. Another study evaluated patients with airway obstruction [27]. Patients were divided to three groups according to their initial FEV1 levels: 0.5-1.0 L $(n=72), 1.15-2.40 \mathrm{~L}(\mathrm{n}=51)$ and 2.45-4.70 L $(\mathrm{n}=27)$ [26]. The natural short-term variability (two measurements within a 20-min interval) in FEV1 did not differ between these groups. The upper limit of the $95 \%$ confidence interval of the absolute variability was $160 \mathrm{~mL}$, and this was not related to sex, smoking status or age. Thereafter, patients with an increase $\geqslant 160 \mathrm{~mL}$ in FEV1BDR were classified as responders, the proportion of which increased significantly with an increasing initial FEV 1 . Then, the $\triangle \mathrm{FEV} 1 \%$ of the initial FEV1 after bronchodilator administration was measured and two cut-off levels (10\% and 15\%) were used. When using the $10 \%$ criterion, the proportion of responders in all three groups with different degrees of initial FEV1 was similar, and in many patients, the increase in FEV1 was indistinguishable from natural variability. However, the criterion of $15 \%$ more often selected those with a low initial FEV1 [27]. These two studies [26, 27] in patients with airway obstructions suggest that the $\triangle \mathrm{FEV} 1 \mathrm{BDR}$ is generally larger than the natural variability or response to placebo, but the sensitivity of 
these cut-off levels may be low, and if cut-off levels that are too low are used, the response may be indistinguishable from natural variability.

\section{Sensitivity of the immediate BDR as a diagnostic marker in asthma}

To evaluate the sensitivity of the obtained cut-off points for asthma diagnostics and to evaluate the overlap between healthy subjects and patients with asthma, the $\triangle \mathrm{FEV} 1 \mathrm{BDR}$ should be studied in therapy-naïve patients without or with regular bronchodilator therapy and asthma diagnosed by the gold standard methodology. We were not able to find any such studies. Few small asthma studies with unclear diagnostic criteria and therapies (total $\mathrm{n}=289$ ) were found and suggested that the mean values of the absolute $\triangle \mathrm{FEV}_{1} \mathrm{BDR}$ varied between $274 \mathrm{~mL}$ and $550 \mathrm{~mL}$; the $\triangle \mathrm{FEV} 1$ calculated from the initial $\mathrm{FEV}_{1}$ varied between $13.7 \%$ and 25.9\%; and the $\triangle \mathrm{FEV} 1$ calculated from the predicted FEV1 varied between $7.8 \%$ and $21.8 \%$ (table S3). In a very recently published study including patients with airway obstruction who were subsequently diagnosed with asthma (diagnostic criteria unknown), the results fall in to the ranges mentioned above [28].

In an Australian population-based cohort study ( $\mathrm{n}=4002$, age $\geqslant 18$ years), the prevalence of current doctor-diagnosed asthma was $9.4 \%(n=380)$ [29]. The prevalence of a positive $\triangle$ FEV1BDR was assessed in four ways: the $\triangle \mathrm{FEV} 1 \%$ of the initial $\mathrm{FEV}_{1}$ was either $\geqslant 12 \%$ or $\geqslant 15 \%$; the $\Delta \mathrm{FEV}_{1} \%$ of the predicted $\mathrm{FEV}_{1}$ was $\geqslant 9 \%$; or the absolute $\triangle \mathrm{FEV} 1 \mathrm{BDR}$ was $\geqslant 400 \mathrm{~mL}$. In current asthma patients (current asthma therapy not withdrawn) and not-current asthma patients, at least one of the criteria for a significant BDR was fulfilled in $6.7 \%$ and $1.3 \%$ of patients, respectively $(\triangle \mathrm{FEV} 1 \mathrm{BDR} \geqslant 400 \mathrm{~mL})$ and $17.9 \%$ and $4.5 \%$ of patients, respectively $\left(\triangle \mathrm{FEV}_{1} \%\right.$ of predicted $\left.\mathrm{FEV}_{1} \geqslant 9.0 \%\right)$. This suggests that the sensitivities of these criteria are low, at least in patients currently on asthma therapy and that all of these criteria may misclassify patients. A $\triangle \mathrm{FEV}_{1} \geqslant 9 \%$ pred identified nearly all patients who were classified by the standard criteria $(\Delta \mathrm{FEV} \mathrm{BDR}$ $\geqslant 12 \%$ or $\geqslant 15 \%$ or $\geqslant 400 \mathrm{~mL}$ ). Furthermore, this study revealed that these four $\triangle$ FEV 1 BDR criteria detect quite different subjects, which may have implications for clinical practice. For example, if the $\triangle \mathrm{FEV} 1 \mathrm{BDR}$ $\geqslant 400 \mathrm{~mL}$ was the only significant response, most subjects were young males aged $<35$ years. The standard criteria for the $\triangle \mathrm{FEV}_{1} \%$ of the initial $\mathrm{FEV}_{1} \geqslant 12 \%$ or $\geqslant 15 \%$ were biased towards detecting younger subjects. Thus, the authors suggest a need for age-specific cut-offs when using these criteria [29]. The use of the $\triangle \mathrm{FEV}_{1} \%$ of the predicted $\mathrm{FEV}_{1}$ has been proposed to eliminate this age-related problem [4]. However, even the criterion of the $\triangle \mathrm{FEV}_{1} \%$ of the predicted $\mathrm{FEV}_{1} \geqslant 9 \%$ missed $6 \%$ of patients identified as having a $\triangle \mathrm{FEV} 1 \mathrm{BDR} \geqslant 400 \mathrm{~mL}[29]$.

\section{Discussion}

Asthma affects a vast number of adults. Most patients are diagnosed with asthma as adults [8, 9], remission is rare [30,31] and the majority of patients are not well controlled [31]. Adult asthma is a lifelong burden; thus, the diagnosis should be made carefully and objectively [1], and if possible, before starting treatment to avoid a misdiagnosis [32]. The diagnosis of asthma has been based on the medical history, typical symptoms and reversibility of airway obstruction measured most often by the $\triangle \mathrm{FEV} 1 \mathrm{BDR}$. A cut-off value of $12 \%$ for the $\triangle \mathrm{FEV}_{1} \%$ of the initial FEV1BDR has been used as a categorical diagnostic test. However, the current evaluation of guidelines and the evidence behind their recommendations indicates that even though there is some agreement regarding the upper 95th percentile of the $\triangle \mathrm{FEV} 1 \mathrm{BDR}$ in healthy persons, the current method of expressing the $\triangle \mathrm{FEV} 1 \mathrm{BDR}$ (absolute and percentage calculated from the initial FEV1) may not be optimal. Furthermore, there is a lack of data to assess the sensitivity and specificity of any of the $\triangle \mathrm{FEV} 1 \mathrm{BDR}$ cut-off points used in the diagnosis of asthma, and the amount of overlap in the $\triangle \mathrm{FEV} 1 \mathrm{BDR}$ between patients with asthma and healthy subjects or those with other lung diseases is not known.

The latest British asthma guidelines state that there is no definitive evidence on the most appropriate choice of algorithm for making a diagnosis of asthma in clinical settings [13]. However, the traditional cut-off of $\triangle \mathrm{FEV}_{1} \%$ of the initial $\mathrm{FEV}_{1} \geqslant 12 \%$ with volume increase of $\geqslant 200 \mathrm{~mL}$ has been used since 1991 [3] and is still regarded as strongly suggestive of asthma, although some COPD patients meet the same criterion [13]. In the recent National Institute for Health and Care Excellence document, the same thresholds for a positive $\triangle \mathrm{FEV} 1 \mathrm{BDR}$ test are recommended, even though they are not diagnostic for asthma alone [14]. In the current GINA report, many methods to confirm variable expiratory airflow limitations are mentioned, one of which is a $\triangle \mathrm{FEV} 1 \mathrm{BDR}$ of $>12 \%$ and $>200 \mathrm{~mL}$ from the initial level (greater confidence if the $\Delta \mathrm{FEV} 1$ is $>15 \%$ and $>400 \mathrm{~mL}$ ) [6].

In five population-based studies, where the possibility of obstructive disease was ruled out (nonsmokers and no questionnaire-based asthma or other lung disease) [21-25], the mean and median $\Delta \mathrm{FEV} 1 \%$ of the initial FEV1BDR were between $1.8 \%$ and $3.4 \%$. The upper 95th percentiles for the absolute $\triangle \mathrm{FEV} 1 \mathrm{BDR}$ varied between $240 \mathrm{~mL}$ and $320 \mathrm{~mL}$, and the $\triangle \mathrm{FEV}_{1} \%$ of the initial $\mathrm{FEV}_{1}$ varied between $5.9 \%$ and $13.3 \%$. 
In four of these studies, the upper 95th percentiles for the $\triangle \mathrm{FEV}_{1} \%$ of the predicted FEV 1 were calculated, and the variation between the reported values was smaller, ranging between $8.7 \%$ and $11.6 \%[21,22,24$, 25]. Recently, Quanjer et al. [24] proposed that this problem ( $\triangle \mathrm{FEV} 1 \%$ of the initial $\mathrm{FEV}_{1}$ being dependent on age and sex) might be avoided by using the change in the $\mathrm{z}$-score for the FEV 1 for evaluating a BDR. However, the data obtained from healthy persons (cut-off points described earlier) differentiate between a normal and abnormal $\triangle$ FEV1BDR, but not necessarily between healthy subjects and those with a specific disease (e.g. asthma) or between subjects with different diseases.

There is still lack of consensus regarding how to express and measure the $\triangle F E V_{1} B D R$. Different methods of measuring the $\triangle \mathrm{FEV}{ }_{1 B D R}$ may identify different kinds of patients [29]. Until now, the most commonly used method was the absolute volume of the $\triangle \mathrm{FEV} 1 \mathrm{BDR}$ and the $\triangle \mathrm{FEV}_{1} \%$ of the initial FEV1. However, studies from the late 1960 s to the 1990 s show that the $\triangle \mathrm{FEV} 1 \%$ of the initial FEV1 can be biased [19, 21, $33,34]$. One of the first reports of standardisation of lung function testing [4] showed that a more reliable estimate of the $\triangle \mathrm{FEV} 1 \mathrm{BDR}$ can be obtained when the improvement in the FEV1 and/or FVC is both $>12 \%$ predicted and $>200 \mathrm{~mL}$. In addition, there are some preliminary data to suggest that this approach may allow better discrimination between patients with asthma and COPD, even though the patient populations are not well characterised $[34,35]$. Recent large population-based studies have also supported the use of the $\triangle \mathrm{FEV}_{1} \%$ pred $[22,24,25,36]$ or the change in the $\mathrm{z}$-score, the latter also eliminating the effect of age [24]. In addition, a FVCBDR may be more relevant than a FEV1BDR, especially in older subjects if they have severe airway obstruction [24].

For a practising clinician, it is important to know the sensitivity and specificity of the diagnostic test in use. To obtain the sensitivity of the recommended $\triangle$ FEV1BDR cut-off points for asthma diagnostics and to evaluate the overlap between healthy subjects and patients with asthma, the $\triangle F E V 1 B D R$ should be studied in therapy-naïve patients with asthma diagnosed by the gold standard methodology or, if such a method does not exist, by other relevant methods. However, the guidelines on the role of the $\triangle \mathrm{FEV} 1 \mathrm{BDR}$ for diagnosing asthma are not based on studies of therapy-naïve newly diagnosed adult patients with asthma to assess the sensitivity of this test for diagnosing asthma. If asthma patients were included in these studies, there was lack of information regarding the age of asthma onset, duration of the disease, atopic status or previous anti-inflammatory medication treatment $[19,28,33,34,37,38]$. Thus, the sensitivity of the $\triangle$ FEV1BDR as a diagnostic tool for asthma remains unknown. The $\triangle$ FEV1BDR may not be a very sensitive tool for the confirmation of current asthma, as $82 \%$ of patients with current asthma (lacking detailed information) did not demonstrate a significant $\triangle$ FEV1BDR, even though $29 \%$ of them had moderate-to-severe respiratory symptoms [29]. Thus, the $\triangle$ FEV1BDR is an imperfect tool for screening for asthma among the general population. A Danish study [39] involving mainly atopic young adults whose inhaled corticosteroids were not withdrawn suggested that the sensitivity of the $\triangle$ FEV1BDR $(>12 \%$ and $>200 \mathrm{~mL}$ ) as a diagnostic marker may not be very high (13\% positive). Instead, the specificity (93\%) appeared to be high for the diagnosis of asthma versus no asthma. The authors propose that different diagnostic methods including peak flow follow-up and provocation tests should be combined to diagnose asthma objectively and reliably [39]. However, the use of a combination of diagnostic tests does not reduce the need for knowledge on the accuracy, sensitivity and specificity of the cut-off-points. In future studies, it will be crucial to elucidate how the diagnosis is made and whether the patients are treatment-naive or not. Currently, many confounding basic factors and missing data make it difficult to compare and interpret the results of the $\triangle$ FEV1BDR studies performed so far for application in clinical practice.

Taken together, we conclude that in population-based studies in healthy persons, the upper 95th percentile of the absolute $\triangle$ FEViBDR varied between $240 \mathrm{~mL}$ and $320 \mathrm{~mL}$, and that of the $\triangle \mathrm{FEV} 1 \%$ of the initial FEV 1 varied between $5.9 \%$ and $13.3 \%$. In four population-based studies, the $\triangle \mathrm{FEV} 1 \%$ of the predicted FEV1 was measured, and the results varied less, from $8.7 \%$ to $11.6 \%$. Several studies prefer expressing a $\mathrm{BDR}$ as the $\triangle \mathrm{FEV}_{1} \%$ of the predicted $\mathrm{FEV}_{1}$ or the change in the $\mathrm{z}$-score to overcome the influence of age, sex, height and level of obstruction on the appropriate cut-off value. There are no relevant published data to assess the sensitivity or specificity of any cut-off level of the $\triangle \mathrm{FEV} 1 \mathrm{BDR}$ for diagnosing asthma or for the differential diagnosis of other lung diseases. Further studies involving treatment-naïve patients with a new asthma diagnosis or suspicion of asthma are needed to assess the actual properties of BDRs as asthma diagnostics and for differentiating between obstructive pulmonary diseases and their phenotypes.

Conflict of interest: L.E. Tuomisto reports non-financial support (costs for attending an international congress) from Chiesi, Boehringer Ingelheim, Orion Pharma and TEVA, and personal fees for lecturing from Astra Zeneca, outside the submitted work. P. Ilmarinen reports grants and lecture fees from Astra Zeneca, and lecture fees from MundiPharma and Orion, outside the submitted work. L. Lehtimäki reports personal fees from AstraZeneca, Boehringer Ingelheim, Chiesi, GSK, Mundipharma, Novartis, OrionPharma, Teva and ALK, outside the submitted work. M. Tommola reports personal fees for lecturing from Astra Zeneca, Filha ry, GSK and Pfizer, personal fees for lectures and consulting from Boehringer Ingelheim, and grants from Orion Research Foundation, outside the submitted work. H. Kankaanranta 
reports fees for lectures and consulting, costs for attending an international congress and research grant to institution from AstraZeneca, personal fees for consulting from Chiesi Pharma AB and Roche, fees for lectures and consulting, and costs for attending an international congress from Boehringer Ingelheim, personal fees for lectures and consulting from Novartis, personal fees for lecturing from Mundipharma and Orion Pharma, outside the submitted work.

Support statement: Supported by the Finnish Anti-Tuberculosis Association Foundation (Helsinki, Finland), Tampere Tuberculosis Foundation (Tampere, Finland), Jalmari and Rauha Ahokas Foundation (Helsinki), the Research Foundation of the Pulmonary Diseases (Helsinki), the Competitive State Research Financing of the Expert Responsibility Area of Tampere University Hospital (Tampere) and the Medical Research Fund of Seinäjoki Central Hospital (Seinäjoki, Finland). None of the sponsors had any involvement in the planning, execution, drafting or composition of this study. Funding information for this article has been deposited with the Crossref Funder Registry.

\section{References}

Reddel HK. Treating according to asthma control: does it work in real life? Clin Chest Med 2012; 33: 505-517.

2 Aaron SD, Vandemheen KL, FitzGerald JM, et al. Reevaluation of diagnosis in adults with physician-diagnosed asthma. JAMA 2017; 317: 269-279.

3 American Thoracic Society. Lung function testing: selection of reference values and interpretative strategies. $A m$ Rev Respir Dis 1991; 144: 1202-1218.

4 Quanjer PH, Tammeling GJ, Cotes JE, et al. Lung volumes and forced ventilatory flows. Report Working Party Standardization of Lung Function Tests, European Community for Steel and Coal. Official Statement of the European Respiratory Society. Eur Respir J 1993; 6: Suppl. 16, 5-40.

5 Pellegrino R, Viegi G, Brusasco V, et al. Interpretative strategies for lung function tests. Eur Respir J 2005; 26 : 948-968.

6 Global Initiative for Asthma. Global Strategy for Asthma Management and Prevention. https://ginasthma.org/ wp-content/uploads/2016/01/wms-GINA-2017-main-report-tracked-changes-for-archive.pdf Date last accessed: February 15, 2017.

7 Hopp RJ, Pasha MA. A literature review of the evidence that a $12 \%$ improvement in FEV1 is an appropriate cut-off for children. J Asthma 2016; 53: 413-418.

8 Sood A, Qualls C, Schuyler M, et al. Adult-onset asthma becomes the dominant phenotype among women by age 40 years. Ann Am Thorac Soc 2013; 10: 188-197.

9 Kankaanranta H, Tuomisto LE, Ilmarinen P. Age-specific incidence of new asthma diagnoses in Finland. J Allergy Clin Immunol Pract 2017; 5: 189-191

10 de Nijs SB, Venekamp LN, Bel EH. Adult-onset asthma: is it really different? Eur Respir Rev 2013; 22: 44-52.

11 Kankaanranta H, Kauppi P, Tuomisto LE, et al. Emerging comorbidities in adult asthma: risks, clinical associations, and mechanisms. Mediators Inflamm 2016; 2016: 3690628.

12 Ilmarinen P, Tuomisto LE, Kankaanranta H. Phenotypes, risk factors, and mechanisms of adult-onset asthma. Mediators Inflamm 2015; 2015: 514868.

13 British Thoracic Society (BTS), Scottish Intercollegiate Guidelines Network (SIGN). BTS/SIGN British Guideline on the Management of Asthma. www.brit-thoracic.org.uk/standards-of-care/guidelines/btssign-british-guidelineon-the-management-of-asthma/ Date last accessed: January 8, 2018. Date last updated: November, 2018.

14 National Institute for Health and Care Excellence (NICE). Asthma: Diagnosis, Monitoring and Chronic Asthma Management. London, NICE, 2017.

15 Snider GL, Woolf CR, Kory RC, et al. Criteria for the assessment of reversibility in airways obstruction. Report of the Committee on Emphysema American College of Chest Physicians. Chest 1974; 65: 552-553.

16 Morris AH, Kanner RE, Crapo RO, et al. Clinical Function Testing: a Manual of Uniform Laboratory Procedures. 2nd Edn. Salt Lake City, Intermountain Thoracic Society, 1984.

17 National Heart, Lung, and Blood Institute. Expert Panel Report 3: Guidelines for the Diagnosis and Management of Asthma. Full Report 2007. www.nhlbi.nih.gov/guidelines/asthma/asthgdln.pdf Date last accessed: April 12, 2018.

18 Levy ML, Quanjer PH, Booker R, et al. Diagnostic spirometry in primary care: proposed standards for general practice compliant with American Thoracic Society and European Respiratory Society recommendations. Prim Care Respir J 2009; 18: 130-147.

19 Brand PL, Quanjer P, Postma DS, et al. Interpretation of bronchodilator response in patients with obstructive airways disease. Thorax 1992; 47: 429-436.

20 Dompeling E, Van Schayck CP, Molema J, et al. A comparison of six different ways of expressing the bronchodilating response in asthma and COPD; reproducibility and dependence of prebronchodilator FEV1. Eur Respir J 1992; 5: 975-981.

21 Dales RE, Spitzer WO, Tousignant P, et al. Clinical interpretation of airway response to a bronchodilator. Epidemiologic considerations. Am Rev Respir Dis 1988; 138: 317-320.

22 Tan WC, Vollmer WM, Lamprecht B, et al. Worldwide patterns of bronchodilator responsiveness: results from the Burden of Obstructive Lung Disease study. Thorax 2012; 67: 718-726.

23 Kainu A, Lindqvist A, Sarna S, et al. FEV1 response to bronchodilation in an adult urban population. Chest 2008; 134: 387-393.

24 Quanjer PH, Ruppel GL, Langhammer A, et al. Bronchodilator response in FVC is larger and more relevant than in FEV1 in severe airflow obstruction. Chest 2017; 151: 1088-1098.

25 Torén K, Bake B, Olin AC, et al. Measures of bronchodilator response of FEV1, FVC and SVC in a Swedish general population sample aged 50-64 years, the SCAPIS Pilot Study. Int J Chron Obstruct Pulmon Dis 2017; 12: 973-980.

26 Sourk RL, Nugent KM. Bronchodilator testing: confidence intervals derived from placebo inhalations. Am Rev Respir Dis 1983; 128: 153-157.

27 Tweeddale PM, Alexander F, McHardy GJR. Short term variability in FEV1 and bronchodilator responsiveness in patients with obstructive ventilatory defects. Thorax 1987; 42: 487-490.

28 Zhang S, Hu C, Lu R, et al. Diagnostic accuracy of bronchodilator response for asthma in a population of south China. Adv Ther 2018; 35: 1578-1584. 
29 Appleton SL, Adams RJ, Wilson DH, et al. Spirometric criteria for asthma: adding further evidence to the debate. J Allergy Clin Immunol 2005; 116: 976-982.

30 Rönmark E, Lindberg A, Watson L, et al. Outcome and severity of adult onset asthma - report from the obstructive lung disease in northern Sweden studies (OLIN). Respir Med 2007; 101: 2370-2377.

31 Tuomisto LE, Ilmarinen P, Niemelä O, et al. A 12-year prognosis of adult-onset asthma: Seinäjoki Adult Asthma Study. Respir Med 2016; 117: 223-229.

32 Hollingsworth HM, O'Connor GT. Asthma - here today, gone tomorrow? JAMA 2017; 317: 262-263.

33 Nicklaus TM, Burgin WW Jr, Taylor JR. Spirometric tests to diagnose suspected asthma. Am Rev Respir Dis 1969; 100: 153-159.

34 Eliasson O, Degraff AC Jr. The use of criteria for reversibility and obstruction to define patient groups for bronchodilator trials. Influence of clinical diagnosis, spirometric, and anthropometric variables. Am Rev Respir Dis 1985; 132: 858-864.

35 Meslier N, Racineux JL, Six P, et al. Diagnostic value of chronic obstruction to separate asthma from chronic bronchitis: a statistical approach. Eur Respir J 1989; 2: 497-505.

36 Ward H, Cooper BC, Miller MR. Improved criterion for assessing lung function reversibility. Chest 2015; 148: 877-886.

37 Pellegrino R, Rodarte JR, Brusasco V. Assessing the reversibility of airway obstruction. Chest 1998; 114: $1607-1612$.

38 Ouksel H, Meslier N, Badatcheff-Coat A, et al. Influence of predicted FEV1 on bronchodilator response in asthmatic patients. Respiration 2003; 70: 54-59.

39 Backer V, Sverrild A, Ulrik CS, et al. Diagnostic work-up in patients with possible asthma referred to a university hospital. Eur Clin Respir J 2015; 2: doi: 10.3402/ecrj.v2.27768. 